\title{
Participant understanding and recall of informed consent for Induced Pluripotent Stem Cell biobanking.
}

Tristan McCaughey, ${ }^{1,2}$ Christine Chen, ${ }^{2}$ Elisabeth De Smit, ${ }^{1}$ Gwyneth Rees, ${ }^{1}$ Eva Fenwick, ${ }^{1}$ Lisa S Kearns, ${ }^{1}$ David A Mackey ${ }^{5,6}$ Casimir MacGregor, ${ }^{7}$ Megan Munsie, ${ }^{8}$ Anthony L Cook, ${ }^{9}$ Alice Pébay, ${ }^{1,5 \#}$ Alex W Hewitt. ${ }^{1,5,6 \#}$

1.Centre for Eye Research Australia, University of Melbourne, Royal Victorian Eye and Ear Hospital, Melbourne, Australia

2. Department of Surgery, Monash University, Victoria, Australia.

3. Singapore Eye Research Institute, Singapore National Eye Centre, Singapore

4. Duke-NUS Medical School, Singapore

5. Lions Eye Institute, University of Western Australia, Perth, Australia.

6. Menzies Institute for Medical Research, University of Tasmania, Australia.

7. School of Social Science, Monash University, Victoria, Australia.

8.Stem Cells Australia, Department of Anatomy and Neuroscience, The University of Melbourne,

Parkville 3010, Australia

9. Wicking Dementia Research and Education Centre; University of Tasmania, Australia.

\# These authors jointly supervised this work.

\section{ADDRESS FOR CORRESPONDENCE:}

Dr Alex Hewitt

Centre for Eye Research Australia

Royal Victorian Eye and Ear Hospital

32 Gisborne Street,

East Melbourne,

Victoria, Australia 3002

Telephone: $\quad+61399298157$

Fax: $\quad+61399298711$

Email: hewitt.alex@gmail.com

Running Title: Consent understanding in iPSC research

MeSH Terms: Induced Pluripotent Stem Cells, HeLa, biobank, iPSCs, Consent, Participant information 


\section{ABSTRACT:}

BACKGROUND: The ability to generate human induced pluripotent stem cells (iPSCs) has opened new avenues for human disease modelling and therapy. The aim of our study was to determine research participants' understanding of the information given when donating skin biopsies for the generation of patient-specific iPSCs.

METHODS: A customised 35-item questionnaire based on previous iPSC consent guidelines was sent to participants who had previously donated samples for iPSC research. The questionnaire asked pertinent demographic details, participant's motivation to take part in iPSC research and their attitudes towards related ethical issues.

RESULTS: 234 participants were contacted with 141 (60.3\%) complete responses were received. The median duration between recruitment and follow-up questioning was 313 days (range 10 to 573 days). The majority of participants $(n=129,91.5 \%)$ believed they understood what a stem cell was; however, only $22(16.1 \%)$ correctly answered questions related to basic stem cell properties. We found no statistically significant difference in responses from participants with different levels of education, or those with a health sciences background.

CONCLUSION: The poor understanding amongst participants of iPSC research is unlikely to be unique to our study and may impact future research if not improved. As such, there is a need to develop an easily understood yet comprehensive consent process to ensure ongoing ethical progress of iPSC biobanking. 


\section{INTRODUCTION:}

The derivation of human induced pluripotent stem cells (iPSCs) is enabling extensive progress in disease modelling and cell-based therapies.(Park et al., 2008; Takahashi et al., 2007; Yu et al., 2007). Given that these cells can be derived from almost any individual without the use of embryonic tissue, they are thought of as an ethical alternative to human embryonic stem cells. Nonetheless, unique ethical issues arise from the use of iPSCs, such as the sharing of samples with external investigators or pharmaceutical companies; the generation of chimeric animals; future uses of cells beyond that outlined in the consent process; and financial gains from commercialization of individual samples. As the now infamous case involving Henrietta Lacks demonstrated (McCarthy, 2013), it is crucial to ensure research participants give informed consent and understand the broad and specific implications of their involvement.

Although ongoing breakthroughs in disease modelling and therapy will be achieved using iPSCs (Kobold et al., 2015), it is becoming increasingly clear that to facilitate such research, samples from a large number of participants will be required (Rouhani et al., 2014). While the donation of cells to derive iPSCs does not raise any specific ethical questions itself, important issues relating to the applications of samples must be communicated to participants. These relate to immortalisation of cell lines, participant privacy, sharing of biospecimens, reproductive research, and animal experimentation (Aalto-Setala et al., 2009). With informed consent guidelines and recommendations in iPSC research well established (Aalto-Setala et al., 2009; Lomax et al., 2015; Lowenthal et al., 2012) and research confirming that these issues are important to the general public (Dasgupta et al., 2014), there is a pressing need to determine the efficacy of current consent procedures.

Previous studies suggest that consent understanding and recall is generally poor amongst study participants in medical research (Khan et al., 2014); however, it is unclear whether this is the case for informed consent involving iPSCs. To date, our research group has collected a large repository of biospecimens for iPSC research. Therefore, the aim of this study was to investigate the informed consent recall and understanding of these participants. Furthermore, we sought to determine what demographic and personal factors affected consent recall. We also explored participants' primary motivation for volunteering to provide a sample for this iPSC research, and their perception of the applications of stem cell technology. 


\section{MATERIALS AND METHODS:}

Study Design and Participant Recruitment:

Ethics approval was obtained from the Royal Victorian Eye and Ear Hospital Human Research and Ethics Committee (RVEEH HREC - 11/1031H) and the Monash University Human Research Ethics Committee (MUHREC - CF15/1206). For the purpose of this study, we investigated the informed consent recall and understanding of participants who had previously provided a skin biopsy to our research facility between May 2013 and April 2015. iPSC samples were collected primarily for ophthalmic research purposes and included both those taken from normal controls as well as patients diagnosed with inherited eye conditions.

Prior to their participation in ophthalmic iPSC research, all participants were provided an information sheet and brochure outlining key aspects of the research (Supplementary Items 1 and 2), a consent form as well as a revocation of consent form (available on request). At the time of their specimen collection, participants underwent an informed consent procedure based upon the work of Aalto-Setälä and colleagues (Aalto-Setala et al., 2009). On the day of collection the purpose of the research was conveyed verbally by one of two investigators (LSK, AWH). Participants were also asked if they had any questions relating to the research or their sample.

\section{Data Collection:}

A 35-item questionnaire was designed to assess participants' understanding of the consent process, motivation to partake in research, and attitude towards ethical issues associated with the research (Supplemental Item 3). This questionnaire was based on the participant information sheet given at the time of their original consent, as well as previously published focus group discussion and iPSC consent guidelines (Dasgupta et al., 2014; Lowenthal et al., 2012).

The customised questionnaire comprised four sections. The first section recorded demographic information, including age, gender, religion and level of education. Furthermore, to assess participants' personal investment in the research, they were asked whether they or a family member were affected with an ophthalmic condition relevant to the research. The second section asked specific details about the consent process undertaken on the day of their specimen collection. This included their motivation for participating; whether they had read the information sheet and in how much detail; their perceived understanding of the consent information; the most useful source of information; and the details of any supplementary information they accessed outside of what was given by the research team. 
Section three allowed participants to rate their general attitudes and understanding of stem cell research on nine questions using a four-point Likert scale ranging from 'Strongly Agree' to 'Strongly Disagree'. An 'I don't know' option was also provided. These questions asked for participants' specific attitudes towards embryonic stem cell research; reproductive cloning from stem cells; and research which could lead to cell replacement therapy. Three questions from section three assessed participants' knowledge of key points in the consent process including expectation of financial or personal benefit and the ability to withdraw from research.

The fourth section included eleven questions with the options of 'True', 'False' or 'Unsure' and further assessed participants' understanding and recall of the actual consent procedure itself. Questions included in this section tested basic knowledge of stem cells, such as their indefinite lifespan and their ability to differentiate into other tissues in the body; use of animals in experiments; pharmaceutical company involvement in research; whether their sample may lead to cell replacement therapy or used for reproductive cloning, where they are used to generate gametes; sharing of samples with other scientists; and whether their sample could be injected into other people. Finally, participants were given the option to comment on how the team could improve the consent process.

To refine the questionnaire, a Thinking-Aloud Cognitive Testing method was applied (Collins, 2003). Five participants were successively interviewed with Cognitive Testing to assess their understanding and interpretation of each question. The questionnaire was updated following each interview, and the wording and format of five questions were changed, with no updates deemed necessary after the final two interviews. Readability analysis (Table 1) found that the final questionnaire had a Gunning Fog Score of 7.7 (www.readability-score.com accessed 4 May 2015), which suggests our questionnaire should have been understandable by all participants.

Participants were administered the final questionnaire either electronically by email or via a hardcopy sent to their last known postal address. A hardcopy of the questionnaire was also posted to participants who did not respond to the email within two weeks.

\section{Data Analysis:}

Understanding of consent information was gauged by results from fourteen questions in the last two sections of the questionnaire. For the final section's dependent variables, we collapsed the five-point Likert scale to a three-point scale ("disagree", "neutral", "agree") merging the "strongly agree" and "agree" options and the "strongly disagree" and "disagree" options. Questions gauging comprehension 
were labelled as 'correct' or 'incorrect' depending on the appropriate answer to each question. For quantitative analysis, 'unsure' and 'I don't know' answers were grouped in the 'incorrect' category.

Data were processed using Statistical Package for the Social Sciences, IBM (version 23.0; SPSS Inc.,

Chicago, IL, USA). Associations between consent recall and variables such as time since consent and skin sample collection, level of education, family history of genetic disease or medical condition, a background in health sciences, perceived understanding of consent and accessing additional sources of information about the study were calculated using the Pearson Chi Squared Test. Attitudes towards applications of stem cell research were compared to variables such as religious affiliation and a personal or family history of genetic disease. Results were considered significant at $\mathrm{P}<0.05$.

\section{RESULTS:}

A total of 234 participants who had previously donated a skin biopsy were contacted for the current study. Each was sent a questionnaire. $153(65.4 \%)$ responses were received, and of these, 141 (92.2\%) had completed at least the first two sections in full and therefore were included in the analysis. The median duration between skin biopsy and follow-up questioning was 313 days (range 10 to 573 days), whilst the self-reported median time since biopsy was 365 days (range 10 to 1095 days). Table 2 displays the demographic details of respondents.

One hundred and three (73.0\%) participants did not access any additional information prior to providing a skin biopsy for iPSC research, and $88(85.4 \%)$ stated that this was because of trust in the research team. When questioned about the most useful source of information, 80 (57.6\%) participants stated speaking to the research team on the day of sample collection, whilst 55 (39.6\%) reported that the information sheet was most beneficial. $115(81.6 \%)$ participants stated that they had read the entire information pamphlet at least once.

A total of $132(93.6 \%)$ participants reported feeling adequately informed following the consent process and $136(97.8 \%)$ participants felt able to ask questions. A large proportion $(129,91.5 \%)$ of subjects believed they understood what is meant by the term "stem cell"; however, only 22 (16.1\%) people knew that their sample could be maintained indefinitely and $71(51.8 \%)$ understood that it could be differentiated into any other cell in the adult body (Figure 1). Participants reported understanding of the term "stem cell," yet this was not associated with their comprehension of sample immortality or pluripotency $(\mathrm{p}>0.05)$. 
Demographic factors such as level of education, background in health science or being personally affected by an ophthalmic disease were not associated with the number of correct responses ( $p>0.05)$. Additionally, time since skin biopsy was not associated with consent recall or understanding about stem cell biology ( $p>0.05) .104$ (75.9\%) respondents were aware that their samples would be used to help develop new treatments and tests, but only 41 (29.9\%) appreciated that pharmaceutical companies could be involved in this process. Only 25 (18.2\%) people were aware of specific aspects explicitly stated in the participant information sheet, such as the fact that animals may be used in the research.

The overall motivation to participate appeared to be generally altruistic, with 131 (92.9\%) people stating that contributing to medical research and the community was their primary reason for participating. Furthermore, 118 (84.9\%) participants stated they did not expect to financially benefit from any discoveries; however, 66 (47.5\%) participants reported that they were hoping to personally benefit from the study. Being personally affected by an inherited disease was not significantly associated with the support of embryonic stem cell research $(\mathrm{p}>0.05)$.

Almost all participants $(137,98.6 \%)$ supported cell replacement therapy, with $113(81.3 \%)$ supporting the research use of embryos derived from IVF samples and 43 (30.9\%) supporting reproductive cloning. Overall, having a religious affiliation was not significantly associated with acceptance of these applications. However, subgroup analysis confirmed that people with a Catholic faith had less support for embryonic stem cell research $(\mathrm{p}=0.005)$ and research involving reproductive cloning $(\mathrm{p}=0.047)$.

\section{DISCUSSION:}

With ongoing iPSC-related research, the number of people providing samples is steadily increasing. As such, it is important to ensure that iPSC consent procedures are both comprehensive and easily understandable. Our study suggests there is generally a poor level of understanding surrounding iPSC consent information amongst iPSC study participants. These findings support previously published work regarding understanding of informed consent in research (Khan et al., 2014; Robinson et al., 2013; Tam et al., 2015) and other areas of medicine, including prescription of medication, preoperative surgical information and emergency treatment (Dathatri et al., 2014; Glicksman et al., 2014; Li et al., 2014).

Our study highlighted a marked discordance between perceived understanding, and actual understanding of the information provided during the informed consent process, with participants generally overestimating their knowledge regarding stem cells. Other studies have reported a similar disconnect 
between perceived and actual understanding (Sepucha et al., 2010); however, this is not consistent throughout the literature with studies showing that satisfaction with the consent process may be a predictor of better recall (Johnson et al., 2011). It has been reported that high levels of trust in the study team increase participants' perceived level of understanding (Sepucha et al., 2010), and this could potentially account for our observations. Despite almost all respondents in this study reporting they felt able to ask questions, it would appear that they do not take this opportunity to explore important issues when they believe they are already well informed.

In contrast to other work (Ahsanuddin et al., 2015; Crepeau et al., 2011; Fink et al., 2010), no single demographic factor was significantly associated with consent understanding or recall in our current study. This may indicate that iPSC consent understanding is more dependent on the consent process than individual participant factors; however, further research using a longitudinal study design is required to establish causation. It could also reflect the fact that our study population was relatively homogenous. Interestingly, we found that the majority of respondents did not access any information beyond what was provided during the consent process. This underscores the importance of detailed, yet comprehensible consent procedures.

We found that participants with moral objections to issues such as reproductive cloning performed better when tested on this in the comprehension section of our questionnaire. This may indicate that these individuals are likely to be engaged during the consent process in issues they feel strongly about. Given the traditional resistance of the Catholic church towards some aspects of reproductive medicine, it was not surprising that people with such a religious affiliation reported less support for IVF embryonic stem cell research and reproductive therapy than those of any other faith. In contrast, there was universal acceptance of cell replacement therapy, highlighting the wide public acceptance of this application of research, and alleviating some concerns that people may be resistant to donating cells that will become an integral part of another human (Aalto-Setala et al., 2009).

Obtaining informed consent is crucial in any research involving human volunteers (2013) and although all samples were wilfully provided, there would appear to be great room to improve the consent understanding of iPSC study participants. Key issues raised by experts in the field such as immortalisation of cell lines, sharing of biospecimens and animal experimentation were some of the least understood areas of consent. These findings may partly be due to the length of time between participation and the follow-up questionnaire, with studies showing that consent recall decreases with time (LavelleJones et al., 1993). Importantly however, we found that people who completed the questionnaire within 
six months of skin biopsy did not appear to have a significantly greater recall or understanding of this work. Given the indefinite nature of individual samples, it is important that consent recall does not lapse dramatically. The potential to recontact participants has been raised by a number of researchers, particularly if samples are used for applications not addressed in the original consent process (AaltoSetala et al., 2009; Lowenthal et al., 2012). The poor recall we have found may indicate a need to revisit consent at particular times if samples will be used into the future. Further research is required to establish whether participants are interested in being reminded of key points of their consent, as well as updates in the precise applications of their samples.

There may have been considerable recall bias due to the retrospective nature of our study. Additionally, it is important to note the differences in demographic details between people who participated in this ancillary study versus those who did no, suggesting some response bias (Table 2). Furthermore, a single study population is unlikely to be completely representative of all iPSC research participants; however, we feel that our results would be reflected in other large-scale iPSC projects. Nonetheless, despite our consent procedures being based on published guidelines (Aalto-Setala et al., 2009; Dasgupta et al., 2014; Lowenthal et al., 2012), our protocols may not directly mirror other researchers' procedures, and therefore findings may differ in other studies. Finally, further research will be required to determine whether the poor comprehension demonstrated is truly a lack of understanding or simply an ambivalence to these issues by the donors.

Despite the fact that information relevant for ensuring adequate iPSC informed consent has been explored in great detail (Aalto-Setala et al., 2009; Dasgupta et al., 2014; Lowenthal et al., 2012), our results suggest that this information is not being well absorbed by study participants. These findings have important implications on effective communication in iPSC informed consent. Indicating that the time-intensive production of written consent information is not achieving desired levels of participant understanding. With ongoing breakthroughs in stem cell science and molecular techniques, researchers must ensure that future progress is not hindered by inadequate informed consent obtained whilst a biomedical technology is in a nascent stage. Alarmingly, it would appear that participants do not understand aspects of iPSC research despite a perceived belief that they are well informed. Ongoing work, investigating improved methods for communicating all aspects of iPSC research to participants, is clearly required. 


\section{ACKNOWLEDGEMENTS:}

This work was supported by grants from a National Health and Medical Research Council (NHMRC) project grant (1059369), the BrightFocus Foundation, Retina Australia, the Ophthalmic Research Institute of Australia and the Clifford Craig Medical Research Trust. EF, GR and AWH are funded by NHMRC Fellowships, whilst AP is supported by an Australian Research Council Future Fellowship. CERA receives operational infrastructure support from the Victorian Government.

The authors declare no potential conflicts of interest related to this work. 


\section{REFERENCES:}

(2013). World Medical Association Declaration of Helsinki: ethical principles for medical research involving human subjects. JAMA 310, 2191-2194.

Aalto-Setala, K., Conklin, B.R., and Lo, B. (2009). Obtaining consent for future research with induced pluripotent cells: opportunities and challenges. PLoS Biol 7, e42.

Ahsanuddin, S., Bento, S., Swerdlow, N., Cervera, I., and Kayler, L.K. (2015). Candidate comprehension of key concepts in kidney transplantation. Ann Transplant 20, 124-131.

Collins, D. (2003). Pretesting survey instruments: an overview of cognitive methods. Qual Life Res 12, 229-238.

Crepeau, A.E., McKinney, B.I., Fox-Ryvicker, M., Castelli, J., Penna, J., and Wang, E.D. (2011). Prospective evaluation of patient comprehension of informed consent. J Bone Joint Surg Am 93, e114(111-117).

Dasgupta, I., Bollinger, J., Mathews, D.J., Neumann, N.M., Rattani, A., and Sugarman, J. (2014). Patients' attitudes toward the donation of biological materials for the derivation of induced pluripotent stem cells. Cell Stem Cell 14, 9-12.

Dathatri, S., Gruberg, L., Anand, J., Romeiser, J., Sharma, S., Finnin, E., Shroyer, A.L., and Rosengart, T.K. (2014). Informed consent for cardiac procedures: deficiencies in patient comprehension with current methods. Ann Thorac Surg 97, 1505-1511; discussion 1511-1502.

Fink, A.S., Prochazka, A.V., Henderson, W.G., Bartenfeld, D., Nyirenda, C., Webb, A., Berger, D.H., Itani, K., Whitehill, T., Edwards, J., et al. (2010). Predictors of comprehension during surgical informed consent. J Am Coll Surg 210, 919-926.

Glicksman, J.T., Sherman, I., and Rotenberg, B.W. (2014). Informed consent when prescribing medication: a randomized controlled trial. Laryngoscope 124, 1296-1300.

Johnson, M.R., Singh, J.A., Stewart, T., and Gioe, T.J. (2011). Patient understanding and satisfaction in informed consent for total knee arthroplasty: a randomized study. Arthritis Care Res (Hoboken) 63, 10481054.

Khan, A., Capps, B.J., Sum, M.Y., Kuswanto, C.N., and Sim, K. (2014). Informed consent for human genetic and genomic studies: a systematic review. Clin Genet 86, 199-206.

Kobold, S., Guhr, A., Kurtz, A., and Loser, P. (2015). Human embryonic and induced pluripotent stem cell research trends: complementation and diversification of the field. Stem Cell Reports 4, 914-925. 
Lavelle-Jones, C., Byrne, D.J., Rice, P., and Cuschieri, A. (1993). Factors affecting quality of informed consent. BMJ 306, 885-890.

Li, F.X., Nah, S.A., and Low, Y. (2014). Informed consent for emergency surgery--how much do parents truly remember? J Pediatr Surg 49, 795-797.

Lomax, G.P., Hull, S.C., and Isasi, R. (2015). The DISCUSS Project: Revised Points to Consider for the Derivation of Induced Pluripotent Stem Cell Lines From Previously Collected Research Specimens. Stem Cells Transl Med 4, 123-129.

Lowenthal, J., Lipnick, S., Rao, M., and Hull, S.C. (2012). Specimen collection for induced pluripotent stem cell research: harmonizing the approach to informed consent. Stem Cells Transl Med 1, 409-421.

McCarthy, M. (2013). NIH and family of Henrietta Lacks reach agreement on access to HeLa genome. BMJ 347, f5041.

Park, I.H., Zhao, R., West, J.A., Yabuuchi, A., Huo, H., Ince, T.A., Lerou, P.H., Lensch, M.W., and Daley, G.Q. (2008). Reprogramming of human somatic cells to pluripotency with defined factors. Nature $451,141-146$.

Robinson, J.O., Slashinski, M.J., Wang, T., Hilsenbeck, S.G., and McGuire, A.L. (2013). Participants' recall and understanding of genomic research and large-scale data sharing. J Empir Res Hum Res Ethics $8,42-52$.

Rouhani, F., Kumasaka, N., de Brito, M.C., Bradley, A., Vallier, L., and Gaffney, D. (2014). Genetic background drives transcriptional variation in human induced pluripotent stem cells. PLoS Genet 10, e1004432.

Sepucha, K.R., Fagerlin, A., Couper, M.P., Levin, C.A., Singer, E., and Zikmund-Fisher, B.J. (2010). How does feeling informed relate to being informed? The DECISIONS survey. Med Decis Making 30, $77 \mathrm{~S}-84 \mathrm{~S}$.

Takahashi, K., Tanabe, K., Ohnuki, M., Narita, M., Ichisaka, T., Tomoda, K., and Yamanaka, S. (2007). Induction of pluripotent stem cells from adult human fibroblasts by defined factors. Cell 131, 861-872. Tam, N.T., Huy, N.T., Thoa le, T.B., Long, N.P., Trang, N.T., Hirayama, K., and Karbwang, J. (2015). Participants' understanding of informed consent in clinical trials over three decades: systematic review and meta-analysis. Bull World Health Organ 93, 186-198H.

Yu, J., Vodyanik, M.A., Smuga-Otto, K., Antosiewicz-Bourget, J., Frane, J.L., Tian, S., Nie, J., Jonsdottir, G.A., Ruotti, V., Stewart, R., et al. (2007). Induced pluripotent stem cell lines derived from human somatic cells. Science (New York, NY 318, 1917-1920. 


\section{TABLE AND FIGURE HEADINGS}

Table 1.

Readability indices of participant information sheet and IPSC consent recall questionnaire.

\begin{tabular}{lcc}
\hline Readability Index & Participant Information Sheet & $\begin{array}{c}\text { IPSC consent recall } \\
\text { questionnaire }\end{array}$ \\
\hline Flesch-Kincaid Reading Ease & 52.7 & 66.4 \\
Flesch-Kincaid Grade Level & 9.1 & 5.7 \\
Gunning-Fog Score & 11.8 & 7.7 \\
Coleman-Liau Index & 13.4 & 12.4 \\
SMOG Index & 9.1 & 5.9 \\
Automated Readability Index & 8.4 & 4.6 \\
Average Grade Level & 10.4 & 7.3 \\
\hline
\end{tabular}


Table 2.

Demographic characteristics of participants who completed the questionnaire and those who were not contactable.

\begin{tabular}{|c|c|c|c|}
\hline & $\begin{array}{c}\text { Complete Responses } \\
(n=141)\end{array}$ & $\frac{\text { No Response }}{(n=93)}$ & $P$ value \\
\hline & Mean (Range) & Mean (Range) & \\
\hline Age (years) & $65(27-89)$ & $59(19-89)$ & 0.004 \\
\hline \multirow[t]{2}{*}{ Time Since Biopsy Collection (days) } & $347(10-573)$ & $406(166-661)$ & 0.001 \\
\hline & n $(\%)$ & n $(\%)$ & \\
\hline Females & $61(43.3)$ & 45 (48.4) & 0.441 \\
\hline Religious Affiliation & $91(64.5)$ & NA & - \\
\hline Background in health or medicine & $21(14.9)$ & NA & - \\
\hline Tertiary Educated & $52(36.9)$ & NA & - \\
\hline
\end{tabular}

Abbreviations: n, Number; NA, data not available. 


\section{Figure 1:}

Breakdown of responses for the eight most poorly answered questions are displayed particular to iPSC research participation, based on concordance with the actual research consent.

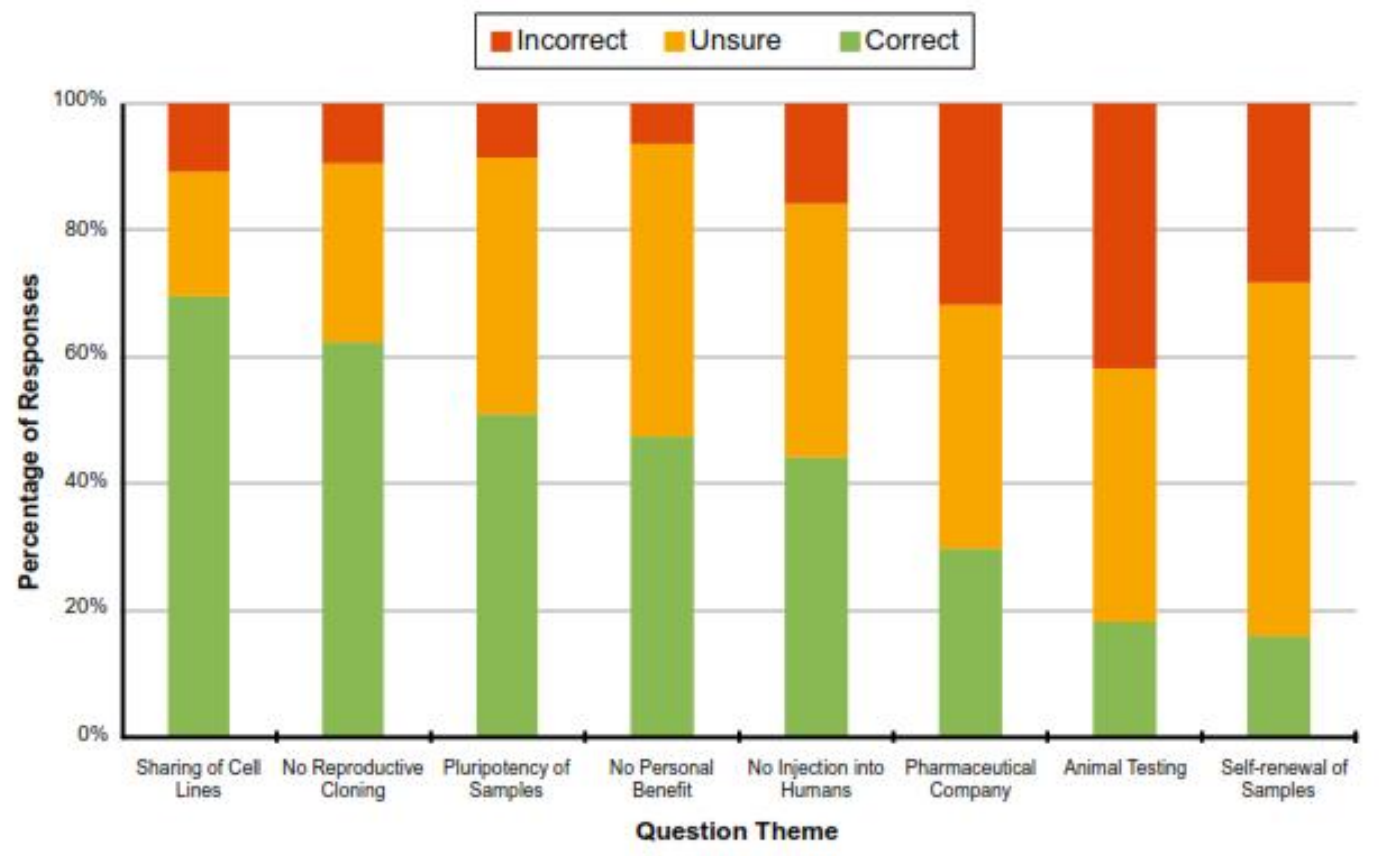




\section{SUPPLEMENTAL INFORMATION}

\section{All Supplemental information is contained in following pages}

\section{Supplemental Item 1}

Participant information sheet

\section{Supplemental Item 2}

Participant information brochure

\section{Supplemental Item 3}

Questionnaire gauging participants' attitudes towards and understanding of iPSC consent. 


\section{PARTICIPANT INFORMATION}

Full Project Title: Derivation and characterization of human induced pluripotent stem cells (iPS) for obtaining eye specific cell lines.

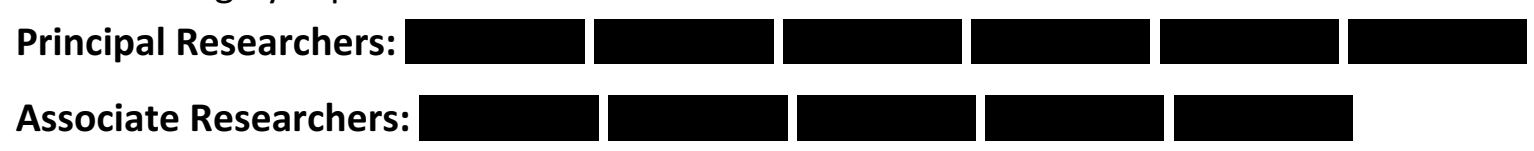

This Participant Information is 5 pages long. Please make sure you have all the pages.

\section{Introduction}

You are invited to take part in this research project. This is because you either have an eye disease or could act as a healthy control participant. The research project is aiming to understand the molecular mechanisms of common blinding disease.

This Participant Information and Consent Form contains detailed information about the research project. Its purpose is to explain to you as openly and clearly as possible all the procedures involved in this project to help you decide whether or not to take part in the research.

Please read this information carefully. Feel free to ask questions about any information in the document that you don't understand or want to know more about. You may also wish to discuss the project with a relative, friend or healthcare worker. Feel free to do this.

Participation in this research is voluntary. If you don't wish to take part, you don't have to. You will receive the best possible care whether you take part or not.

Once you understand what the project is about and if you decide to take part in it, you will be asked to sign the consent section. By signing it, you are telling us that you:

- Understand what you have read;

- Consent to take part in the research project;

- Consent to participate in the research processes that are described;

- Consent to the use of your personal and health information as described.

You will be given a copy of this Participant Information and Consent Form to keep.

\section{Purpose and Background}

The purpose of this project is understand the molecular mechanisms of eye disease.

Induced pluripotent stem cells (iPS) are cells generated in the laboratory, generally from skin cells, that have been reprogrammed and induced to become pluripotent that is, they have the ability to form all cell types of the body. This characteristic makes iPS similar to embryonic stem cells.

The aim of this study is to generate iPS cells from skin biopsies of people with and without eye disease. This will allow the development of stem cell lines that will then be studied to further the understanding of the mechanisms of disease and importantly to identify suitable therapies for people with eye disease.

A total of 1000 people will participate in this project.

You are invited to participate in this research project because either have been diagnosed with an eye disease or have been identified as having no signs or family history of eye disease. 
This research has been initiated by the investigators (

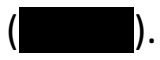

This research also is being conducted in collaboration with as well as who is based at the

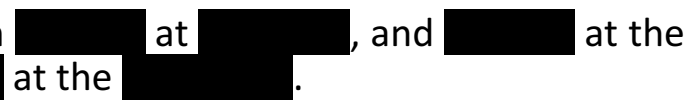

\section{Procedures, and What is Involved}

Should you agree to participate, you will be asked to provide a small skin biopsy or hair sample from which the iPS cells will be derived. In participants aged less than $18 y e a r s$ a hair sample will be taken.

\section{Skin}

The skin biopsy will measure about $3 \mathrm{~mm}$ and be taken from the inside of your forearm. The area will be injected with a local anesthetic prior to the biopsy been taken to minimize pain associated with the procedure. The biopsy area will then be secured with steri-strips and covered with a sterile bandage. We estimate that the time commitment required of you would not exceed 30 minutes. The risks associated with a skin biopsy are minimal however may include bleeding after the procedure and infection of the biopsy site. The risk of bleeding will be minimized through careful technique and the use of aseptic measures will minimize the risk of infection. You will also be provided with contact details of the researcher should any untoward discomfort, excessive bleeding or infection arise after the procedure.

The skin biopsy will then be assigned a code number to protect your confidentiality, be made suitable for maintenance in culture, and processed to obtain the iPS cells. Once successfully generated, the iPS cells will be kept within the laboratory of If If development of these cell lines proves successful the cell lines may be shared with other researchers working in the area of eye disease.

\section{$\underline{\text { Hair }}$}

Participants aged 18 years or less, will be asked to provide a small number of hair follicles. A total of approximately five hair follicles will be plucked from your forehead or arm. There will be a small amount of discomfort at the site. We estimate that the time commitment required of you would not exceed five minutes.

In addition, you may be asked to provide a small sample of blood ( $2 x$ tubes $10 \mathrm{ml}$ ). The blood sample will be collected from a vein in your arm with a needle. Where possible the white blood cells (lymphocytes) will be isolated and a cell line will be made.

Data obtained from your participation will be stored in a de-identified manner. Electronic data will be stored on one computer under password protection. Back up computer data will be stored in a locked cabinet. The data will only be accessible to the investigators named on this Patient Information Sheet.

The data collected in this study can be accessed by members of the Human Research Ethics Committee to audit the study that is being done. Any publications that arise from this study will have information from the study participants as a group and no information that can identify any individual will be included. 


\section{Possible Benefits}

In the short term are unlikely to be any direct benefits to you personally. In the future we envisage that a greater understanding of the disease processes involved in eye disease will enable better treatment modalities.

\section{Possible Risks}

Possible risks, side effects and discomforts include scarring at the site of skin biopsy, bleeding and infection.

- Everyone will have a small $\sim 3 \mathrm{~mm}^{2}$ scar at the biopsy site.

- We expect that less than 1 in 1000 people will get significant bleeding at the biopsy site. If you do notice some bleeding from the biopsy site please elevate and apply pressure to the wound. Should this occur please telephone emergency department.

- We expected that less than 1 in 100 people will develop an infection at the skin biopsy site. If your wound becomes swollen, red, warm or painful please telephone or attend a local emergency department.

- The significant risk associated with hair follicle collection is localised pain or irritation. If your surrounding skin becomes overly irritated or swollen please telephone

or attend a local emergency department.

As a participant you can suspend or even end your participation in this project. Should this occur please contact either one of the study investigators or the secretary of the HREC.

\section{Participation is Voluntary}

Participation in any research project is voluntary. If you do not wish to take part you are not obliged to. If you decide to take part and later change your mind, you are free to withdraw from the project at any stage.

Your decision whether to take part or not to take part, or to take part and then withdraw, will not affect your routine treatment, your relationship with those treating you or your relationship with the

Before you make your decision, a member of the research team will be available to answer any questions you have about the research project. You can ask for any information you want. Sign the Consent Form only after you have had a chance to ask your questions and have received satisfactory answers.

If you decide to withdraw from this project, please notify a member of the research team before you withdraw. This notice will allow that person or the research supervisor to inform you if there are any health risks or special requirements linked to withdrawing.

\section{Results of Project}

We envisage that the results from this work will be presented at scientific meetings or in the published literature. You will not be able to be directly identified from these publications or presentations.

At the conclusion of this immediate work we shall forward a general newsletter updating you with the findings and significant outcomes. 


\section{Privacy, Confidentiality and Disclosure of Information}

All data will be de-identified and all specimens coded with a unique code, which is only known by the Principal Study Investigator. All electronic data will be stored on a password protected computer. Only researchers involved with this work will have access to this de-identified data.

Given that molecular techniques and technology are continuing to advance we do not currently plan to dispose of the stored material. However, ethical approval would be sought for any future work.

Future work could involve the following:

- Injection of iPS cells or derivates into nonhuman animals

- Sharing of cell lines with other researchers, with appropriate confidentiality protections

Any information obtained in connection with this project that can identify you will remain confidential and securely stored. It will only be disclosed with your permission, except as required by law.

We currently have no active plans for any commercial development of the research results. Nonetheless, it is important to note that patenting scientific discoveries developing commercial tests and therapies could be possible, with no sharing of royalties with donors or participants.

In any publication and/or presentation, information will be provided in such a way that you cannot be identified. In accordance with relevant Australian and Victorian privacy and other relevant laws, you have the right to access the information collected and stored by the researchers about you. You also have the right to request that any information with which you disagree be corrected. Please contact one of the researchers named in this document if you would like to access your information.

\section{Injury}

In the event that you suffer an injury as a result of participating in this research project, hospital care and treatment will be provided by the public health service at no extra cost to you if you elect to be treated as a public patient.

\section{Reimbursement for your costs}

You will not be paid for your participation in this research.

\section{Ethical Guidelines}

The ethical aspects of this research project have been approved by the Human Research Ethics Committee of the

This project will be carried out according to the National Statement on Ethical Conduct in Human Research (2007) produced by the National Health and Medical Research Council of Australia. This statement has been developed to protect the interests of people who agree to participate in human research studies. 


\section{Who can I Contact?}

The person you may need to contact will depend on the nature of your query. Therefore, please note the following:

\section{For further information or appointments}

If you require further information concerning this project or if you have any medical problems which may be related to your involvement in the project (for example, any side effects), you can contact the principal investigator

$$
\text { on }
$$$$
\text { or }
$$

\section{For complaints}

If you have any complaints about any aspect of the project, the way it is being conducted or any questions about your rights as a research participant, then you may contact

Position: HREC Secretary

Telephone:

You will need to tell the Secretary the name of one of the researchers listed above.

\section{Reviewing HREC:}

The reviewing HREC approving this research and contact details of the Executive Officer are:

Reviewing HREC name:

Position:

HREC Secretary

Telephone:

Email:

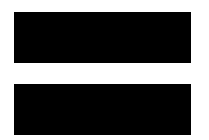


How will we look after your information?

Your sample and clinical information will be held in strict confidence at all times and labeled with a unique study code. Only clinical research staff will be able to link this code to your medical records. Research staff will not be able to identify you as an individual.

What if I have previously participated in research?

It would be useful to obtain a fresh blood sample as DNA from previously collected samples can degrade or may have been completely used. In addition, a skin biopsy was not obtained with previous research work.

What will NOT be done?

No sample or health information will be released to a third party unless it is to carry out research that has been approved by a Human Research Ethics Committee. Information will only be disclosed with your permission, except as required by law.

Will I be told results?

Overall research results will be published in scientific journals and participants will be provided with a newsletter. This will be provided in such a way that you cannot be identified.

Individual results relating to this research which could be important to you or your family will be disclosed as they become available. In most cases results of this work may take many years.

Will I be reimbursed?

You will not be paid or reimbursed for participating in this research. Though there will be no costs and you will not be charged for any testing.

Who is conducting this study?

This is a collaborative project between researchers who are based across Australia:

Centre for Eye Research Australia,

Royal Victorian Eye and Ear Hospital,

Lions Eye Institute, Western Australia,

Flinders University of South Australia,

Save Sight Institute, and the

Menzies Research Institute Tasmania.
Participation

Participation in this research project is voluntary. If you decide to take part and later change your mind, you are free to withdraw from the project.

Does this study have ethics approval?

The ethical aspects of this research project have been approved by the Human Research Ethics Committees of the Royal Victorian Eye \& Ear Hospital, University of Western Australia, Flinders University of South Australia and the University of Tasmania.
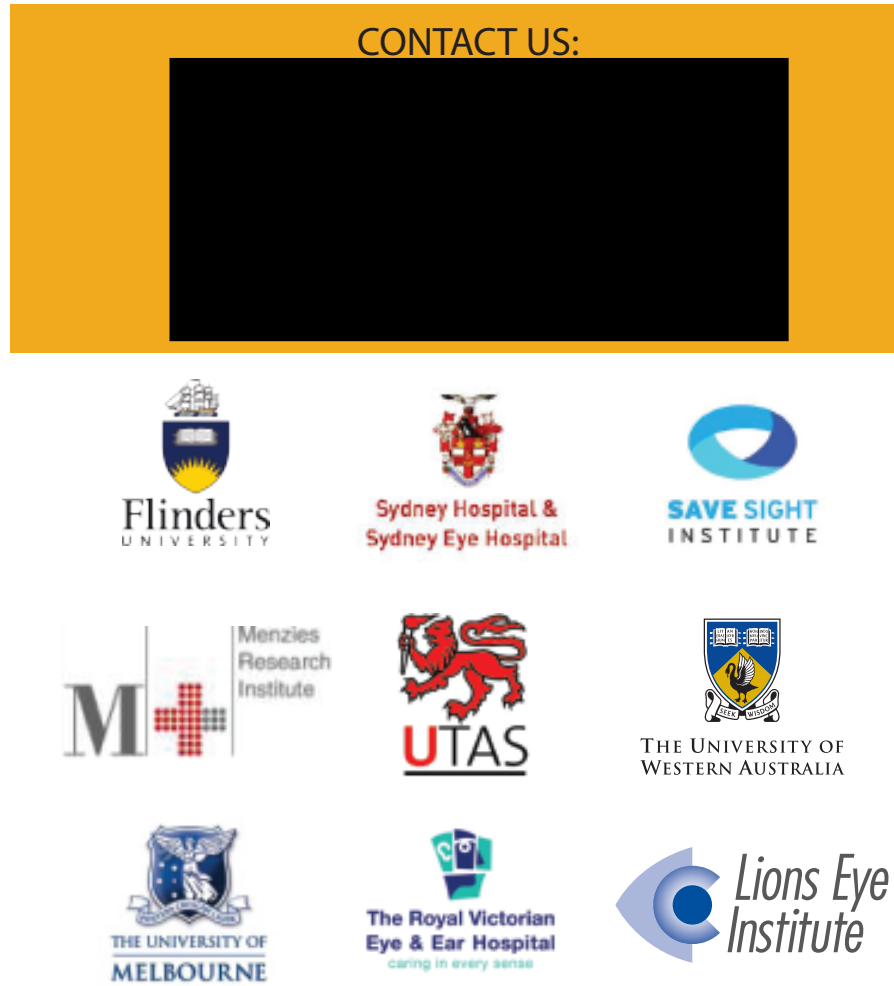

Individualised Stem Cells ... insight into eye disease

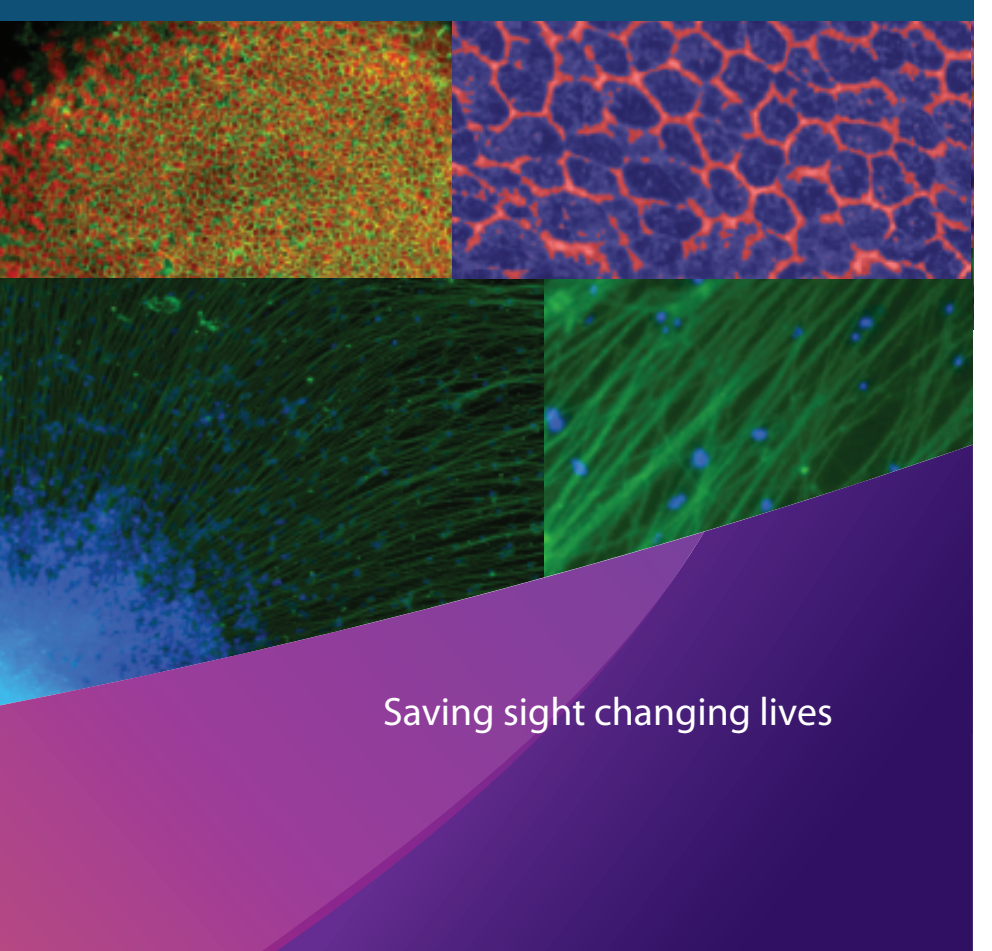


Major breakthrough for studying eye disease:

The extreme difficulty in obtaining eye tissue from living people currently represents a major barrier to the development of new treatments for blinding disease. Recent breakthroughs in stem cell technology have led to the ability to generate stem cells from adult tissue, and these "induced pluripotent stem cells" now represent a more powerful disease modelling tool (and are less ethically contentious) than embryonic stem cells.

Using this new technology it is now possible to take an adult cell (such as a skin cell), turn it into an "induced pluripotent stem cell" and then from that stem cell generate different tissue - such as the nerve or retinal tissues at the back of the eye. This breakthrough is revolutionary as it is now possible to study the cells at the back of your eye without actually needing to take a sample from your eye.

What is the aim of this work?

To enable better treatments we wish to understand how particular eye diseases develop

Who can participate?

1. People who have an eye condition

2. People who could be a carrier or have a family history of an eye condition

3. People who have healthy eyes and no known family history of an eye condition.

By comparing how the cells from people with different eye conditions (or differing risk of eye disease) vary to those from people with healthy eyes, we will be able to identify the mportant gene pathways involved in disease development and explore avenues for new treatments.

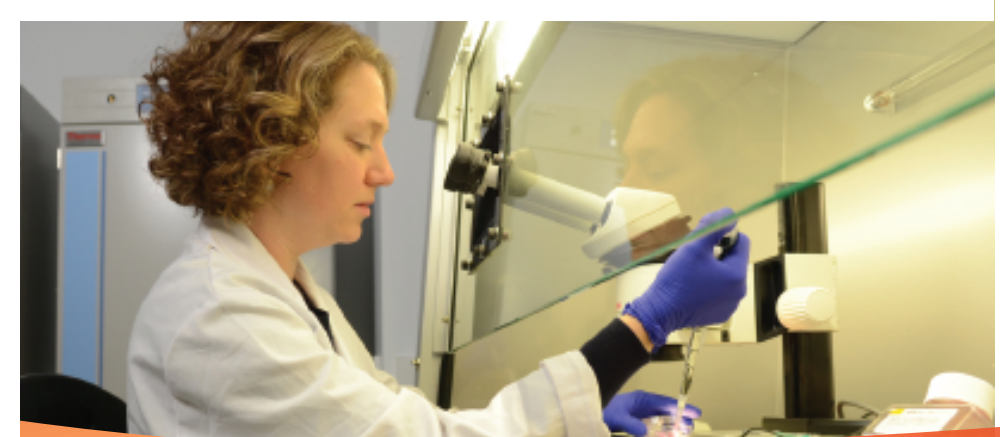

What do we ask of you?

1. Donate approximately $20 \mathrm{mls}$ of blood for research purposes. You do not have to fast.

2. Provide a skin biopsy:

- The skin biopsy will measure $\sim 3 \mathrm{~mm}$ and would generally be taken from the inside of your forearm or upper arm.

- You will receive local anaesthetic for this small procedure. A small scar (about the size of freckle, arrow above) will be left on the area after the procedure.

3. Grant permission to access your identified health information relevant to eye research. Information may originate from the Hospital, private eye doctors, local GPs, or Medicare. We will also ask information about your family history of eye disease.

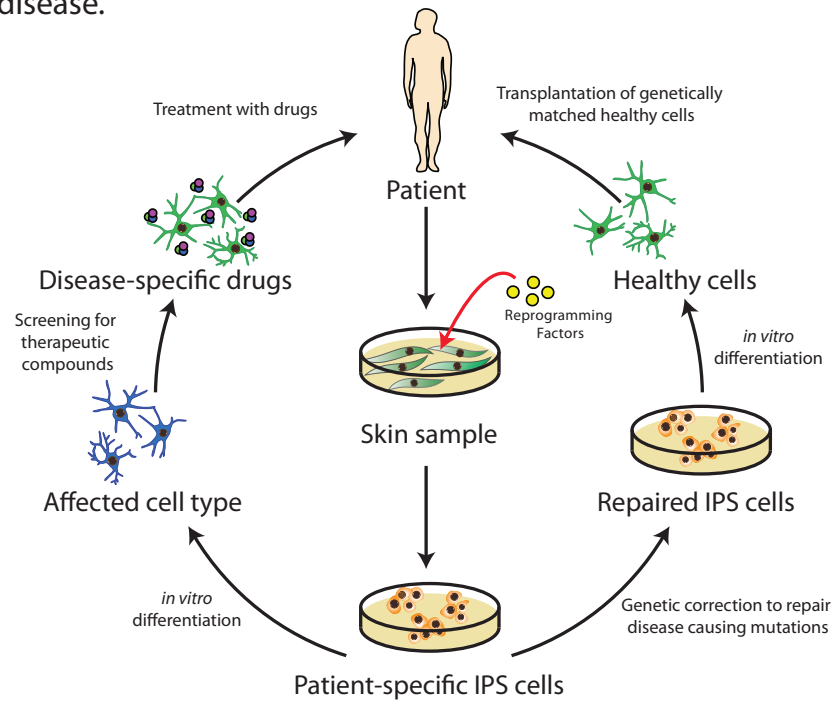

What are the benefits of participating?

In the short term, there will not be any direct benefit to you. However, by participating in this research you are making an important contribution to research that has the potential to minimise vision loss and blindness for others in the future.
What are the risks?

The risks associated with a blood sample and skin biopsy are small: however, bleeding after the procedure and infection of the biopsy site could occur. The risk of bleeding will be minimized through careful technique, and the use of aseptic measures will reduce the risk of infection.

You will also be provided with contact details of the research team should you have any concerns after the sample has been collected.

What will be done with your sample?

During the subsequent months and years, your sample will be analysed for ethically approved eye research. Researchers will analyse your blood sample, including the genetic information (DNA) contained in your blood and skin cells. This, together with the information in your medical records, will enable researchers to learn how your genes relate to different eye conditions and your general health.

Given that molecular techniques and technology are continuing to advance we do not currently plan to dispose of the stored material. However, ethical approval would be sought for any future, currently unforeseen research.

Future work could involve the following:

* Injection of cells or derivatives into nonhuman animals

* Sharing of cell lines with other researchers, with appropriate confidentiality protections

Sometimes research will lead to findings that result in the development of a commercial test or treatment that may be overseen by pharmaceutical companies. Australian law indicates that there can be no financial reward or payment to you in such an event. CERA, as well as the other affiliated research institutes and universities, reinvest any benefits they receive into further medical research. 


\section{Demographic Details}

1. How old are you?

2. What is your gender?

$$
\square \text { Female } \square \text { Male }
$$

3. What is your religious affiliation?

$\square$ None

口 Christian - Protestant

- Christian - Catholic

口 Christian - Other

Muslim

$\square$ Jewish

$\square$ Buddhist

口 Hindu

$\square$ Other (Please specify)

4. Please specify which ethnicity/heritage you identify with?

(Please Specify)

5. Have you ever been diagnosed with an eye or brain disease?

$\square$ No

Yes (Please Specify)

6. Has anyone in your family been diagnosed with an eye or brain disease?

$\square$ No

Y Yes (Please Specify)

Relation:

Condition:

7. What is your highest level of education?

$\square$ Finished primary school

G Finished high school

- Finished course/ apprenticeship

- Finished bachelors degree

$\square$ Finished higher degree

8. Do you have any background in health, medicine or genetic science?

№

प Yes (Please Specify) 


\section{Consent procedure}

9. Approximately how long ago did you give a sample of your skin for this research?

$\square$ I don't remember.

10. Why did you decide to participate in this research? (you may select more than one option)

$\square$ I hope to personally benefit from any treatment discovered.

$\square$ I hope my relatives will benefit from any treatment discovered.

$\square$ I wanted to contribute to medical research and the community.

$\square$ It was recommended by my doctor/ophthalmologist.

$\square$ I hope to gain some financial reward.

$\square$ I hoped to obtain information about my condition and emerging treatment.

$\square$ I don't know

$\square$ Other (please specify)

11. In how much detail did you read the information sheet/pamphlet given to you by the research team?

I I skimmed sections of the information sheet/pamphlet.

- I read or had read to me the whole information sheet/pamphlet once.

- I read or had read to me the information sheet/pamphlet multiple times before my appointment.

I I did not read the information sheet/pamphlet (please state why)

12. Which of the following most accurately describes your feelings about the information sheet/pamphlet given to you by the research team?

口 I found that the information sheet/pamphlet was too complicated and I did not understand much of the information provided.

- I found the information sheet/pamphlet easy to understand and I felt adequately informed after reading it.

- I found the information sheet/pamphlet too simple, I would have prefered to be given more detail about the research and what would be done with my sample.

- I did not read the information sheet/pamphlet

13. What source of information was most useful when finding out about the study?

- The information sheet/pamphlet given to me by the research team.

- Speaking to the researchers on the day my skin sample was taken.

O Other information which I found through my own search.

$\square$ Unsure.

14. What sources of information did you access before donating your skin sample? (you may select more than one option)

- The information provided by the research team.

- I discussed it with a doctor/scientist not involved with the research.

$\square$ I discussed it with a participant who is also involved in the research.

I I discussed it with friends and family with no specialty knowledge of genetic research.

- Information I found online. (If you can remember the website[s] you used, please specify)

$\square$ Other (please specify) 


\section{Please state how strongly you agree with each of the following statements}

15. My level of trust in the research team influenced the amount of additional information I sought regarding this research

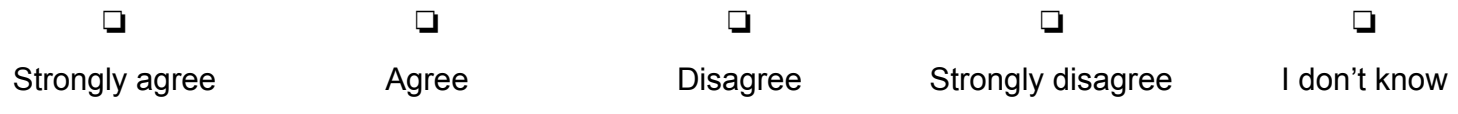

16. I understand what is meant by the term 'stem cell'.

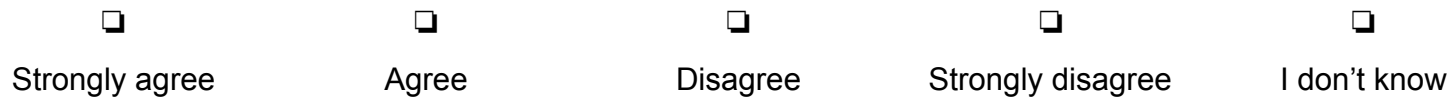

17. I felt able to ask questions during the consent process.

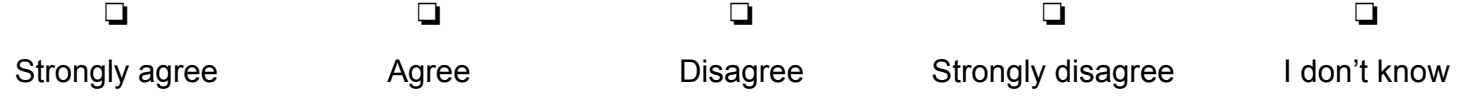

18. I participated in the research hoping to personally benefit from any discoveries.

Strongly agree Agree Disagree Strongly disagree I don't know

19. I support the use in research of embryonic stem cells generated initially for infertility treatment (IVF) which would otherwise not be used.
Strongly agree
Agree
Disagree
Strongly disagree
I don't know

20. I support the use of stem cells in research which could lead to cell replacement therapy, where diseased tissue or cells are replaced with new ones.
Strongly agree
Agree
Disagree
Strongly disagree
I don't know

21. I support the use of stem cells in research involving reproductive cloning (the creation of egg and sperm to create a human foetus)
Strongly agree
Agree
Disagree
Strongly disagree
I don't know

22. I would expect to financially benefit if a new test or treatment was developed using stem cells made from my skin.
Strongly agree
Agree
Disagree
Strongly disagree
I don't know

23. Receiving follow-up information including the results of the study is very important to me.

$\begin{array}{llll}\text { Strongly agree } & \text { Agree } & \text { Disagree } & \text { Strongly disagree I don't know }\end{array}$

24. I am able to have my samples destroyed at any time without any consequence to my medical care. 


\section{From your understanding of the consent procedure, please state whether you feel these} statements to be True or False

25. The stem cells made from my skin can turn into any other type of cell

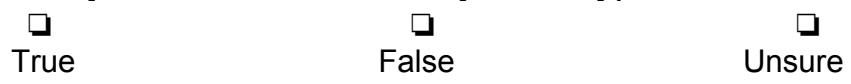

26. My identity is protected by researchers.

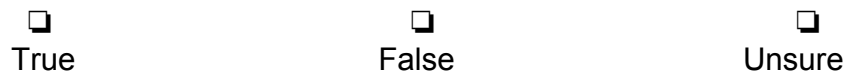

27. I have given consent for stem cells made from my skin to be kept indefinitely.

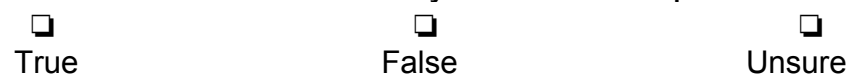

28. I have given consent for stem cells made from my skin to be used in animal experiments.

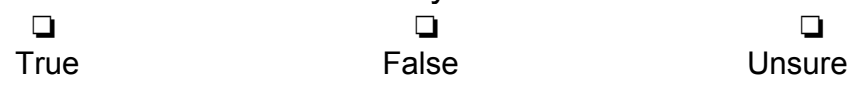

29. I have given consent for stem cells made from my skin to be injected into other people.

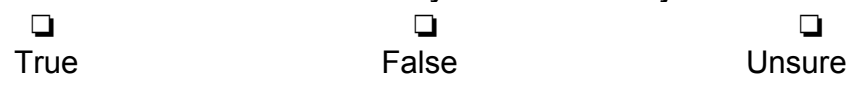

30. I have given consent for stem cells made from my skin to be shared with other scientists involved in ethically approved research projects.

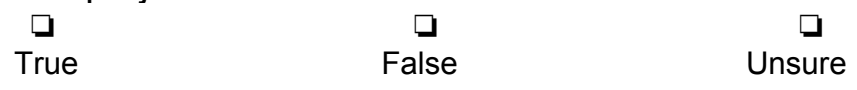

31. I have given consent for stem cells made from my skin to be used by pharmaceutical companies in ethically approved research projects.

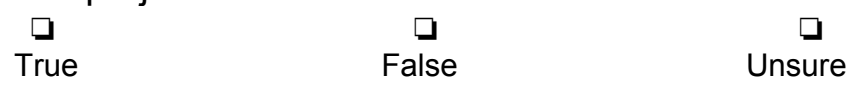

32. I have given consent for stem cells made from my skin to be used to create new treatments and tests.
True
False
Unsure

33. I have given permission for stem cells made from my skin to be used in research involving reproductive cloning (the creation of an egg or sperm to create a human foetus).

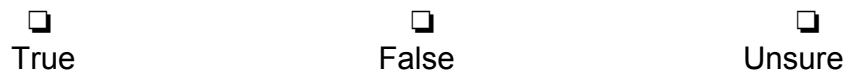

34. I have given permission for stem cells made from my skin to be used in research which could lead to cell replacement therapy, where diseased tissue or cells are replaced with new ones.

$\begin{array}{lc}\square & \square \\ \text { True } & \text { False }\end{array}$

35. A stem cell is a cell which has a limited lifespan.
True
False
Unsure 


\section{Final Information}

36. Do you have any comments on how we could improve the consent process?

\section{Further information}

If you would like any information regarding this questionnaire or the overall research project please tick one of the boxes below.

$\square$ I would like the Stem Cell Research Team to contact me via telephone

$\square$ I would like the Stem Cell Research Team to contact me via email

Alternatively, please feel free to contact the research team directly:

Please Call:

A/Prof Alex Hewitt or Ms Lisa Kearns

Clinical Genetics Unit

Centre for Eye Research Australia

(03) 99298713 or 0407359824 